Article

\title{
The Exploitation of Low-Temperature Hot Water Boiler Sources with High-Temperature Heat Pump Integration
}

\author{
Darko Goričanec ${ }^{1}$, Igor Ivanovski ${ }^{2}$, Jurij Krope ${ }^{1}$ and Danijela Urbancl ${ }^{1, *}$ \\ 1 Faculty of Chemistry and Chemical Engineering, University of Maribor, \\ Smetanova ul. 17, 2000 Maribor, Slovenia; darko.goricanec@um.si (D.G.); jurij.krope@um.si (J.K.) \\ 2 IVD Maribor, Valvasorjeva Ulica 73, 2000 Maribor, Slovenia; igor.ivanovski@ivd.si \\ * Correspondence: danijela.urbancl@um.si
}

Received: 31 October 2020; Accepted: 27 November 2020; Published: 30 November 2020

\begin{abstract}
The article presents an original and innovative technical solution for the exploitation of low-temperature excess heat from hot water boilers that use gas or liquid fuel for the needs of high-temperature heating in buildings or in industry. The primary fuel efficiency used for hot water boilers can be significantly increased by utilizing the excess low-temperature heat of flue gases that are discharged into the environment and thus also reduce $\mathrm{CO}_{2}$ emissions. Hot water systems usually operate at higher temperatures of the heating water, which is transported to the heat consumer via supply pipe, and the cooled heating water is returned to the hot water boiler via the return pipe. For the excess low-temperature heat exploitation of the flue gases from hot water boiler, it is necessary to install a condenser in the flue gas discharge pipe, where condensation of water vapour present in the flue gas heats water or a mixture of water and glycol. The heating water, which is cooled and returned from the heat consumer via the return pipe, is led to the condenser of the high-temperature heat pump, where it is preheated and then led to the hot water boiler, where it is heated to the final temperature. A computer simulation with the Aspen plus software package for the series or parallel connection of high-temperature heat pump to a hot water heating system and the economic analysis of the excess heat exploitation from the flue gases are also performed.
\end{abstract}

Keywords: renewable energy sources; hot water boilers; high-temperature heat pumps; district heating; economic analysis

\section{Introduction}

In the last few decades, much effort has been invested in the European Union (EU) and the rest of the world into achieving cleaner air and consequently, reducing greenhouse gas (GHG) emissions. The use of fossil fuels has brought great pressure on the environment itself, therefore scientists all around the world are investigating new environmentally friendly technologies that would be suitable for high penetration of renewable energies in the energy system [1], because renewable energies have shown huge potential in the reduction of GHG emissions. Several strategies, agreements, protocols, and directives on environmental issues, such as the Paris Agreement [2], European Green Deal [3], or European Energy Efficiency Directive [4] have been signed to navigate all European and other world countries when switching the fossil-fuel-based systems to renewable energy sources, such as solar, wind, bioenergy, or geothermal energy [5].

Moreover, increasing the efficiency of new or existing heat-generation plants is one of the priorities in line with the EU's commitments to reduce GHG emissions and achieve several environmental goals [6]. There are several heat pumps suitable for waste heat exploitation. 
High-temperature heat pumps (HTHP) are coming to the fore as one of the devices with most potential for heat production in efficient way [1,7]. High-temperature heat pumps are devices that make a remarkable contribution to reducing energy dependence since their use is possible in all industries where low-temperature fluid heat fluxes are generated. There are several advantages of using HTHP compared to traditional heating systems, for instance, they provide an economically and environmentally efficient way to exploit low-temperature sources to improve specific energy use in processes, increase efficiency, and reduce $\mathrm{CO}_{2}$ emissions due to lower fossil fuel consumption for heat production. But some disadvantages are presented as well, especially the investment costs. Furthermore, it is believed that both thermal and economic performances of HTHP should be carefully examined in the future.

Many papers in the field of energy efficiency, hot water boilers, high-temperature heat pumps, along with economic and energy analyses have been reported recently [8,9]. Calise et al. [10] have provided an overview of recent progress in assessing sustainable energy systems. Li et al. [11] have analysed the economic and energy efficiency of CHP (cogeneration heat and power) systems with turbine-driven fans and pumps. Liu et al. [7] have developed a mathematics and results have shown that a $\mathrm{CO}_{2}$ heat pump system is economically and ecologically feasible, especially in areas not rich in natural gas.

This research is mainly focused on high-temperature heat pumps [12]. Bergamini et al. [1] studied the thermodynamic performance of various HTHPs based on the vapour compression cycle with natural gas boilers for assessing their technical feasibility and competitiveness as future replacements. Their results have shown that HTHPs are promising substitutes for gas boilers for heat production of temperature up to $180^{\circ} \mathrm{C}$. Moreover, Tańczuk et al. [13] determined the waste energy potential of the slag in the boiler and the proposition of the heat recovery system. In the results, they confirmed that the proposed heat pump provides energy savings.

On the other hand, Luo et al. [5] researched in their work the thermo-economic performance of replacing a coal-fired boiler with a groundwater heat pump (GWHP) system for reducing GHG emission and also to provide cooling. In the work, the authors monitored the system for a year and then both capital and operating costs were evaluated. Their major findings include the results of the boiler efficiency factor, which varied between 0.53 and 0.63 , and coefficient of performance (COP) of the system, which was on average 4.1 for cooling and 3.3 for heating. Moreover, due to the low capital and operational costs, it was concluded that such a system could be used in terms of thermo-economic performances for applications in other places of the world with similar climate conditions.

The main objective of this study is to develop an innovative solution for the exploitation of excess low-temperature heat sources of hot water boilers, which are discharged with exhaust gases into the environment. The heat that would be produced with one or more cascaded high-temperature heat pumps $[14,15]$, by exploiting low-temperature heat sources of hot water boilers, would be used for preheating the return water of the high-temperature heating system in industry or district heating systems.

\section{Low-Temperature Water Exploitation with High-Temperature Heat Pump Integration}

The proposed system of exploiting low-temperature heat sources of hot water boilers with high-temperature heat pumps [16] responds to the needs of the economy. It is an innovative and economically profitable process that stands out for technical excellence. A high-temperature heat pump [17] is used to upgrade low-temperature heat from hot water boiler systems. The excess heat is a source to the higher temperature heat pump, and the produced heat can be used by a heat consumer for space or process heating, preferably in the scope of district heating. According to the study, it is important that the high-temperature heat pumps are used to heat up and raise the temperature of a heat transfer medium in a return line of a heat distribution network.

For example, exploiting low-temperature sources of hot water boiler with one or more single-stage high-temperature heat pumps would be carried out on the hot water boiler, which will be installed in 
the boiler room of the district heating system. The exploiting the low-temperature heat sources of the hot water boiler makes it possible to increase the production of heat up to $17 \%$, without the additional consumption of natural gas.

The principle of exploiting low-temperature sources of the hot water boiler plant with the high-temperature heat pump [18] is shown in Figure 1, where a hot water boiler with an incorporated high-temperature heat pump in a heat distribution network is schematically presented.

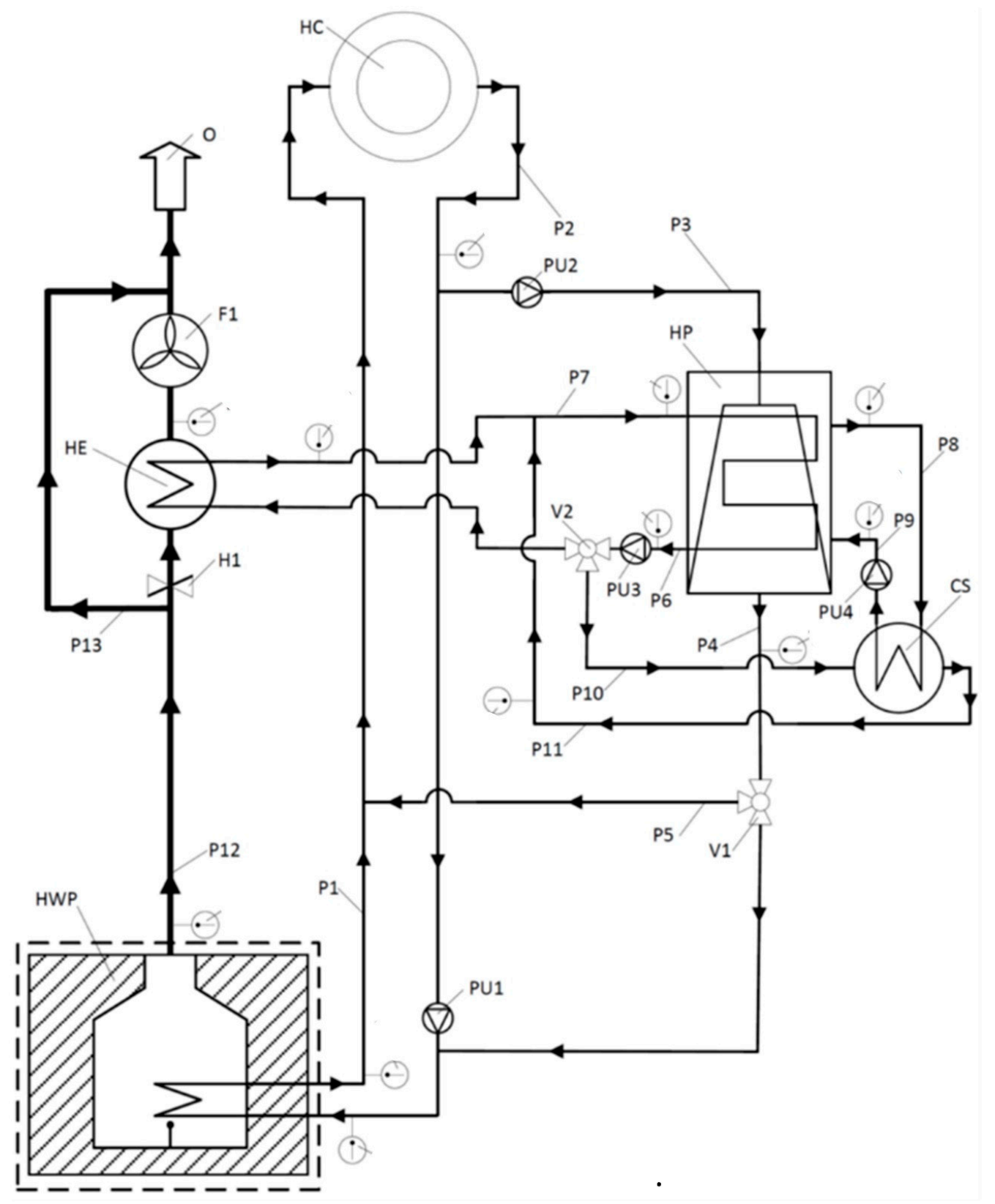

Figure 1. Schematic presentation of a hot water boiler with incorporated high temperature heat pump in a heat distribution network [18].

Figure 1 shows a schematic representation of a hot water plant preferential embodiment with incorporated water source high-temperature heat pump (HP) having a condenser unit, an evaporator unit, and a compressor with adopted lubrication oil cooling system (CS) for high- temperature heat pump principle utilization, where the following items are further shown and marked: hot water boiler (HWB) heat distribution circuit and exhaust system comprising a network of pipes (P1-P13), 
valve (V2) and pumps (PU1-PU4) which interconnects the heat consumer (HC) with stated heat sources, heat exchanger (HE), hatch (H1), fan (F1) and ambient (O).

Referring to the preferential embodiment of the power plant with incorporated water source high-temperature heat pump, the system comprises a furnace with incorporated boiler in the scope of the first heat releasing unit of the hot water boiler, which preferably runs on a gas fuel, such as natural gas, liquefied petroleum gas, fuel oil, landfill gas, wood gas, biogas or coal, for example. While the hot water boiler first heat releasing unit is used for heat generation when powered, a significant amount of heat is released by the flue gas, wherein the heat is either used by a heat consumer rather than discharged and dissipated to the ambient through the exhaust pipe (P12) (i.e., chimney). It is important to notice that the first heat source for a heat consumer is preferably represented by the boiler in the scope of the hot water boiler, having an inlet and outlet aperture, whereby a plurality of excess heat sources arise in the scope of the hot water boiler and incorporated high-temperature heat pump, at least when the hot water boiler and high-temperature heat pump are turned on and powered, preferably at optimal efficiency or full load regime.

According to the preferential embodiment depicted, as represented in Figure 1, the hot water boiler inflow (i.e., inlet port) and outflow (i.e., outlet port) apertures are operable coupled to the closed-loop heating circuit comprising a network of pipes (P1-P11) that operable interconnects the heat consumer and heat sources in the scope of the hot water boiler with incorporated water source high-temperature heat pump. The heat distribution network further comprises a primary heat transfer medium and automated regulation means comprising a control unit (i.e., control electronics), valve (V2), and pumps (PU1-PU4) for primary heat transfer medium streamflow regulation, wherein the heat of heat sources is preferably transferred to the heat consumer by the principle of primary heat transfer medium circulation in the closed-loop heating circuit.

Excess low-temperature heat from the hot water boiler system is not used and is released into the environment through $140{ }^{\circ} \mathrm{C}$ hot flue gas heat. In order to utilise the exhaust gas heat with a temperature of $140^{\circ} \mathrm{C}$, a heat exchanger must be installed in the exhaust gas system of the hot water boiler system, in which the exhaust gases are cooled down to a temperature of $25^{\circ} \mathrm{C}$ by cooling and condensation of the flue gases.

\section{Low-Temperature Heat Source}

The low-temperature heat source of the HTHP is the hot water boiler flue gases, and operating data are given in Table 1. The flue gases are cooled in the condenser of the HP (Figure 1). For this purpose, a computer simulation of the cooling flue gases was performed using the Aspen plus software package. The results are presented in Figures 2 and 3.

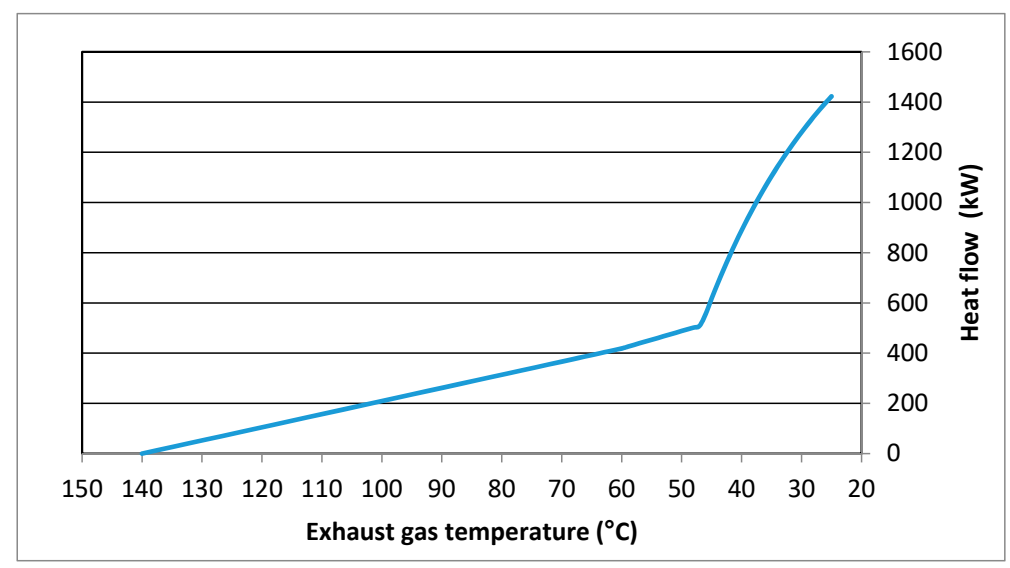

Figure 2. The low-temperature heat flow with an additional cooling of the flue gases hot water boiler (HWB). 


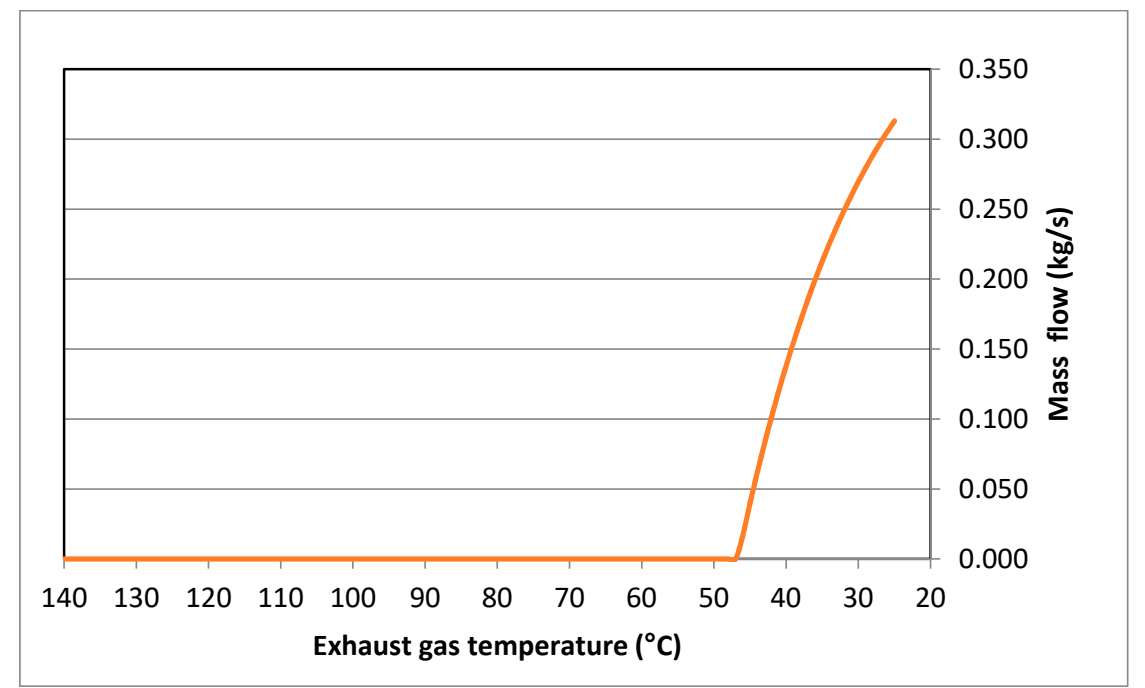

Figure 3. The obtained quantity of condensate with an additional cooling of the flue gases HWB.

Table 1. (A) technical data by the manufacturer of the hot water boiler operating at $100 \%$ and (B) technical data utilization of low-temperature sources hot water boiler (HWB) by high-temperature heat pumps (HTHP).

\begin{tabular}{cccc}
\hline & (A) & (B) & \\
\hline & HWB & HWB + HTHP & \\
\hline Natural gas LHV (low heating value) & 9.5 & 9.5 & $\mathrm{kWh} / \mathrm{Nm}^{3}$ \\
\hline Energy input (LHV) & 8189 & 8189 & $\mathrm{~kW}$ \\
\hline Recoverable thermal output: & & & \\
\hline -Exhaust gas cooled to $140{ }^{\circ} \mathrm{C}$ & 7435 & 7435 & $\mathrm{~kW}_{\text {th }}$ \\
\hline Low temperature available heat & & & \\
\hline -Exhaust gas cooled to $25^{\circ} \mathrm{C}$ & & 1428 & $\mathrm{~kW}_{\text {th }}$ \\
\hline $\begin{array}{c}\text { Exploited low temperature thermal } \\
\text { output }\end{array}$ & & & $\mathrm{kW}_{\text {th }}$ \\
\hline -Heat generated with HTHP $\left(70{ }^{\circ} \mathrm{C}\right)$ & & 314 & $\mathrm{~kW}_{\text {th }}$ \\
\hline -Absorbed power HTHP & & 8863 & $\mathrm{~kW}_{\mathrm{e}}$ \\
\hline Recoverable thermal output: & 7435 & 9160 & $\mathrm{~kW}_{\text {th }}$ \\
\hline Total thermal output & & 108.2 & $\%$ \\
\hline Recoverable thermal efficiency HWB & 90.6 & &
\end{tabular}

To be able to use the low-temperature heat of the flue gas with a temperature of $140{ }^{\circ} \mathrm{C}$, it is necessary to install the condenser heat exchanger in the flue gas system of hot water boilers where the flue gasses are to be cooled to a temperature of $25^{\circ} \mathrm{C}$.

\section{High-Temperature Heat Pump}

High-temperature heat pumps are devices that make a remarkable contribution to reducing energy consumption, as their use is possible in all industries where low-temperature fluid heat fluxes are generated. They provide an economically and environmentally efficient way of harnessing low-temperature sources to improve specific energy use in processes, increase efficiency and, reduce $\mathrm{CO}_{2}$ emissions due to lower fossil fuel consumption for heat production. 
Commercially available high-temperature heat pumps with rated outputs of $500 \mathrm{~kW}, 1.4 \mathrm{MW}$, 4.5 MW, and 9.8 MW [19] and can be used for the excess heat recovery with high-temperature heat pumps of small or more parallel installed large hot water boiler of total power $50 \mathrm{MW}$ or more. The coolant of high-temperature heat pumps is ammonia (R717). The operational data of a $500 \mathrm{~kW}$ high- temperature heat pump are given in Table 2.

Table 2. Summary of the results of the computer simulation of the series connection of high-temperature heat pumps from Figure 2.

\begin{tabular}{cccccc}
\hline HTHP Sequence Number & $\begin{array}{c}\text { Required Power } \\
\text { Compressor (kW) }\end{array}$ & $\begin{array}{c}\text { Compressor } \\
\text { Pressure Ratio (Pa) }\end{array}$ & $\begin{array}{c}\text { Evaporator } \\
\text { Heat Flux (kW) }\end{array}$ & $\begin{array}{c}\text { Condenser } \\
\text { Heat Flux (kW) }\end{array}$ & COP \\
\hline 1 & 74 & 2.74 & 294 & 364 & 4.92 \\
2 & 78 & 2.48 & 342 & 417 & 5.35 \\
3 & 80 & 2.23 & 391 & 466 & 5.82 \\
4 & 81 & 2.13 & 401 & 478 & 5.90 \\
In total & 313 & & 1428 & 1725 & 5.51 \\
\hline
\end{tabular}

\section{Process Simulation with AspenPlus}

To utilize the heat excess of the hot water boiler, a computer simulation of four series-connected high-temperature heat pumps with a nominal power of $500 \mathrm{~kW}$ was performed using the Aspen Plus software package [15]. The operating data of a $500 \mathrm{~kW}$ high-temperature heat pump at a compressor rotation speed of $1450 \mathrm{~min}^{-1}$ are given in [15]. Heat production using the aforementioned high-temperature heat pump can be controlled by a frequency-controlled electric motor drive where a maximum permissible speed of a reciprocating compressor is $1600 \mathrm{~min}^{-1}$.

Schematics of four high-temperature heat pumps with some computer simulation results are presented in Figure 4. In the system, all high-temperature heat pumps are connected in series and they consist of four compressors (COMP1, COMP2, COMP3, COMP4), four refrigerant evaporators (EVAP1, EVAP2, EVAP3, EVAP4), four condensers (COND1, COND2, COND3, COND3), and four expansion valves (VALVE1, VALVE2, VALVE3, VALVE4). It must be mentioned that the low-temperature heat source of those high-temperature heat pumps is water or a mixture of water and glycol, which is heated in the condenser (HE) shown in Figure 1 when using the heat excess of the flue gas of the hot water boiler.

Water or a mixture of water and glycol, which is firstly heated to approximately $50{ }^{\circ} \mathrm{C}$ during the utilization of heat excess from the flue gases of a hot water boiler, is passed successively through all four drains (EVAP1, EVAP2, EVAP3, EVAP4) via pipeline P7 shown in Figures 1 and 4. Later it is cooled down to about $25^{\circ} \mathrm{C}$ and returned to the condenser (HE) via pipeline P6. In each of the four evaporators of high-temperature heat pumps, the evaporation pressure of the coolant (ammonia) is different because it depends on the availability of heat flows obtained by cooling the water in each evaporator. Vapours of refrigerants leaving the evaporators are compressed by compressors (COMP1, COMP2, COMP3, COMP4) to the pressure required to condense the refrigerants in a series-connected condensers (COND1, COND2, COND3, COND4) when heating the heating water. The heating water, as a return of the hot water system, is fed to the first condenser through the pipeline P3 as shown in Figures 1 and 4, and is consequently fed sequentially to each individual condenser of the high-temperature heat pumps. In each condenser, the heating water is heated slightly until the desired temperature is reached in the last condenser. The water of the heating system is then fed to pipeline P4 to a hot water boiler, in which it is heated to the final temperature of the hot water system.

To compare the operating characteristics, a computer simulation of the utilization of heat excess of a hot water boiler with four-series connection high-temperature heat pumps is also made. For a simpler presentation, only one heat pump is used in the computer simulation, and the compressor has the same operating characteristics as four high-temperature heat pump compressors connected in series. 
The scheme of one high-temperature heat pump shown in Figure 5 consists of a single compressor (COMP), a refrigerant evaporator (EVAP), a condenser (COND), and an expansion valve (VALVE). The low-temperature heat source of a high-temperature heat pump is again water or a mixture of water and glycol, which is heated in the condenser (HE) shown in Figure 1. Water or a mixture of water and glycol is heated to approximately $50^{\circ} \mathrm{C}$ and passed to the high-temperature heat pump (EVAP) via pipeline P7 shown in Figures 1 and 4 . When the source is cooled down to $25^{\circ} \mathrm{C}$, it is returned to the condenser (HE) via pipeline P6.

The refrigerant vapours leaving the evaporator (EVAP) are compressed by a compressor (COMP) to the pressure required to condense the refrigerant in the condenser (COND) when heating the return water of the hot water heating system. The return water of the hot water heating system is supplied to the condenser via pipeline P3 shown in Figures 1 and 4. In the condenser, the return water of the hot water heating system is heated to the desired temperature and then returned to the hot water boiler via pipeline $\mathrm{P} 4$, where it is heated to the final temperature.

Effective recovery of excess heat is critical to provide good total utilization of fuel energy, thus, the first and the most important excess heat source is represented by the stream of low temperature flue gas in the exhaust system, which is a product of the combustion process within the hot water boiler. Secondly, there is at least one additional excess heat source represented by high-temperature heat pump compressor lubrication oil cooling systems (CS), which under certain circumstances are still important for good total excess heat source utilization.

Electricity for compressors in high-temperature heat pumps is needed, which can be supplied from the grid, or generated by on a CHP unit if it is located near a boiler room [20-22].

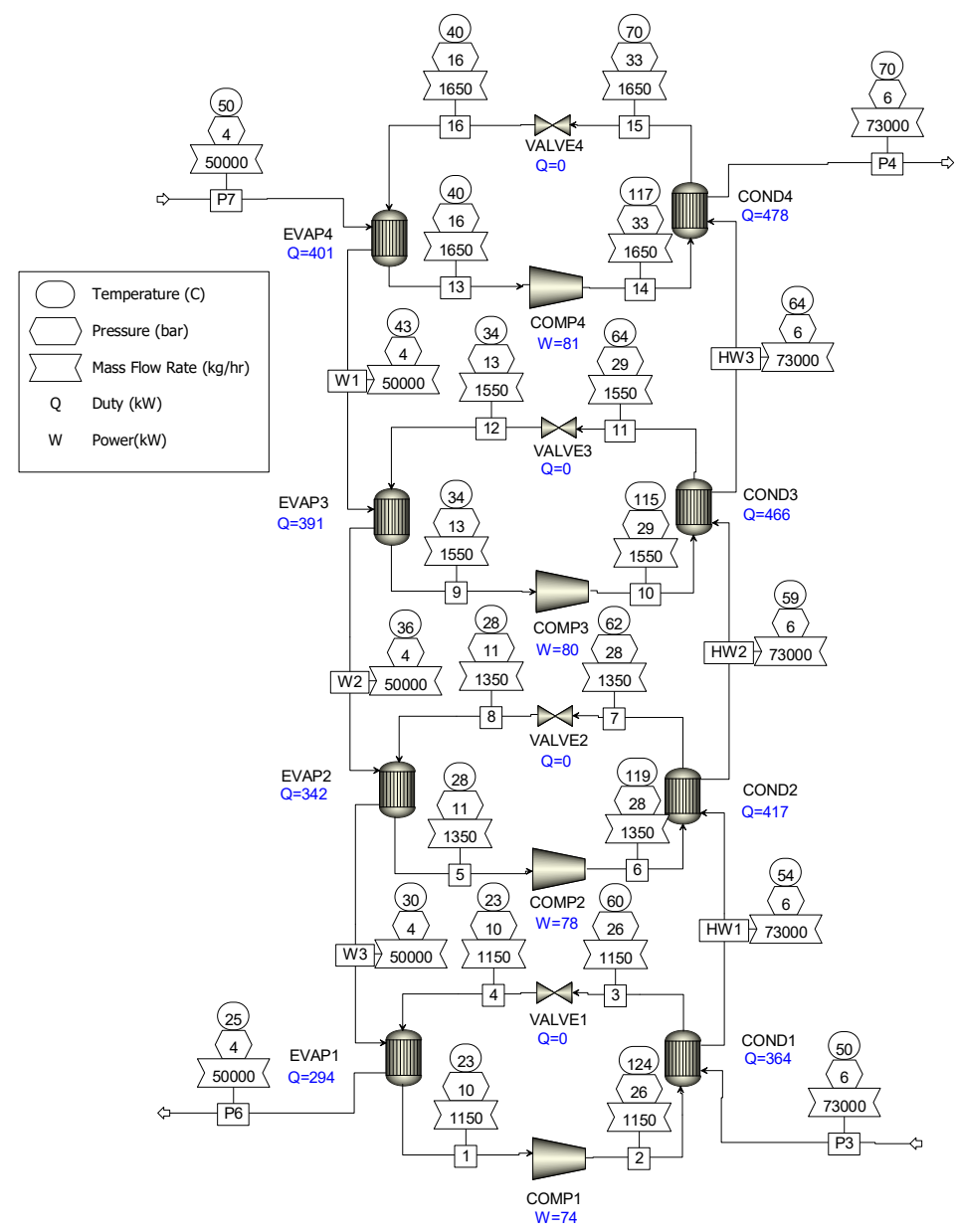

Figure 4. The scene of four series-connected high-temperature heat pumps with the results of computer simulation using the Aspen Plus software package. 


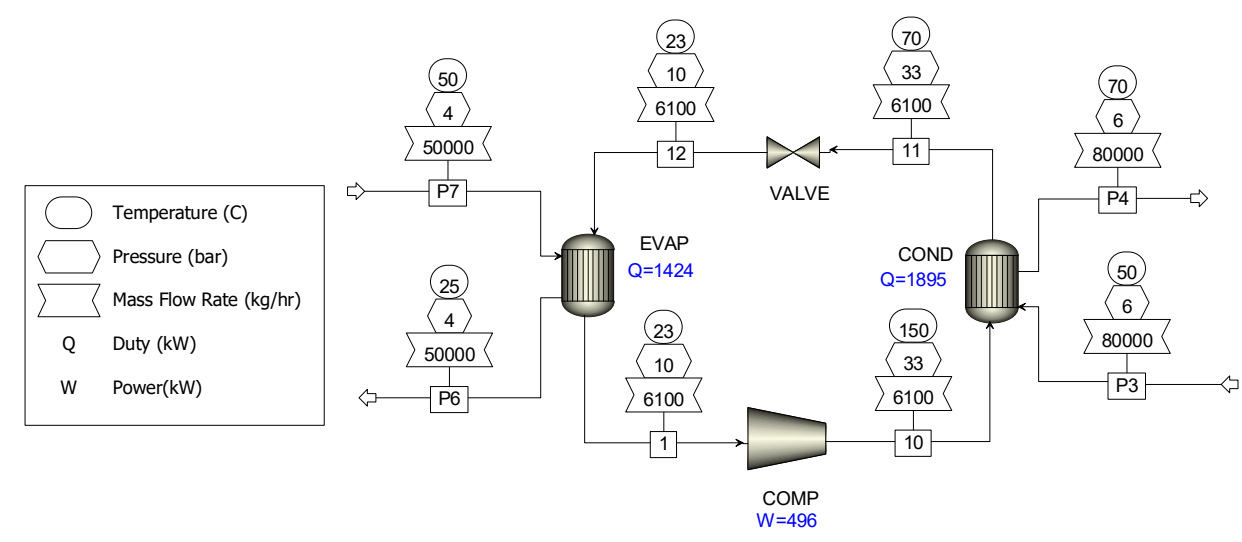

Figure 5. Schematic diagram of a high-temperature heat pump with the results of a computer simulation using the Aspen Plus software package.

Comparison of natural gas efficiencies and the production of a hot water boiler and hot water boiler by utilizing the excess heat with high-temperature heat pumps that use electric power from the grid fora drive of compressors are given in Table 1.

With the cascading installation of four single-stage high-temperature heat pump with a rated output heat of $500 \mathrm{~kW}_{\mathrm{th}}$, can be increased by $1730 \mathrm{~kW}_{\mathrm{th}}$, that is, from $7435 \mathrm{~kW}_{\text {th }}$ to $9165 \mathrm{~kW}_{\text {th }}$ and the total primary energy consumption of natural gas by $17.6 \%$, that is from $90.6 \%\left(7435 \mathrm{~kW}_{\text {th }}\right)$ to $108.2 \%$ $\left(8860 \mathrm{~kW}_{\text {th }}\right)$.

\section{Results and Discussion}

The low-temperature heat source of high-temperature heat pumps are the flue gases of the hot water boiler, which are cooled in the HP condenser shown in Figure 1. The results of the computer simulation of flue gas cooling are given in the form of diagrams in Figures 2 and 3.

It can be seen from the diagrams in Figures 2 and 3 that the flue gases of the hot water boiler are first cooled from a temperature of $140{ }^{\circ} \mathrm{C}$ to a temperature of $48^{\circ} \mathrm{C}$, obtaining approximately $500 \mathrm{~kW}$ of heat. However, the further cooling of the flue gases causes condensation of water vapor, which is present in the flue gases. Most of the heat, about $920 \mathrm{~kW}$, is obtained by cooling the flue gases from $48^{\circ} \mathrm{C}$ to $25^{\circ} \mathrm{C}$, producing about $0.315 \mathrm{~kg} / \mathrm{s}$ of condensate. By further cooling the hot water flue gas to about $5{ }^{\circ} \mathrm{C}$, an additional $800 \mathrm{~kW}$ of heat could be obtained, thereby further increasing the primary fuel efficiency of the hot water boiler to about $117 \%$ relative to the LHV (low heating value) of the natural gas. The temperature to which the flue gases would be cooled depends on the economics of operation of the cascade-connected high-temperature heat pumps, as this would significantly reduce the average COP of the heat pumps.

In case you want to use an additional $800 \mathrm{~kW}$ of heat, you would have to add three more high-temperature heat pumps to the existing four high-temperature heat pumps in Figure 2. By lowering the evaporation temperature of the refrigerant in the evaporator of the high-temperature heat pump, the pressure ratio of the compressor increases, and therefore more power is required for the electric motor drive of the compressor, which results in a lower COP.

To better present an innovative technical solution for exploiting low-temperature sources of a hot water boiler, a computer simulation of four high-temperature heat pumps connected in series is performed in Figure 3 and a computer simulation of one high-temperature heat pump is shown in Figure 4. as if they had four high-temperature heat pumps connected in parallel, which were used in the process simulation in Figure 3. The operating characteristic of one heat pump in Figure 4 is the same as if four high-temperature heat pumps were used in parallel, Figure 3.

A summary of the computer simulation results of the series-connected heat pumps shown in Figure 3 is given in Table 2, and a summary of the results of the computer simulation of one heat pump 
shown in Figure 4 is given in Table 3. The data in Table 2 show that the average COP (coefficient of performance) of all four high temperature heat pumps is 5.51. By lowering the temperature of the low-temperature heat source, the COP of the high-temperature heat pumps also decreases. The calculation was made by heating the return heating water from a temperature of $50{ }^{\circ} \mathrm{C}$ to a temperature of $70{ }^{\circ} \mathrm{C}$ in series-connected condensers of high-temperature heat pumps.

From the results of computer simulation of one heat pump given in Figure 4, a summary is made, which is given in Table 3. The data in Table 3 show that the COP is 3.82, which is much less than series-connected heat pumps. The reason is that it is necessary to overcome the larger temperature difference $\left(\left(\mathrm{T}=50^{\circ} \mathrm{C}\right)\right.$ between the low-temperature heat source and the desired heating water return temperature with a high-temperature heat pump. This also requires more electrical power to drive the electric motor of the high-pressure compressor, because it is necessary to create a higher pressure ratio between the pressure at the evaporation temperature and the pressure at the condensing temperature of the refrigerant with the compressor.

Table 3. Summary of the results of the computer simulation of the high-temperature heat pump from Figure 3.

\begin{tabular}{cccccc}
\hline HTHP Sequence Number & $\begin{array}{c}\text { Required Power } \\
\text { Compressor (kW) }\end{array}$ & $\begin{array}{c}\text { Compressor Pressure } \\
\text { Ratio (Pa) }\end{array}$ & $\begin{array}{c}\text { Evaporator Heat } \\
\text { Flux (kW) }\end{array}$ & $\begin{array}{c}\text { Condenser Heat } \\
\text { Flux (kW) }\end{array}$ & \begin{tabular}{c} 
COP \\
\hline 1
\end{tabular} \\
\hline 196 & 3.47 & 1424 & 1896 & 3.82 \\
\hline
\end{tabular}

\section{Economics}

The economic efficiency of using low-temperature heat sources from a selected hot water boiler system with the HTHP was calculated in MS Excel. Some companies produce heat with a CHP plant, therefore the economic efficiency for the example is calculated as if the electricity is produced by CHP. Electricity prices vary from country to country. Two calculations have been made:

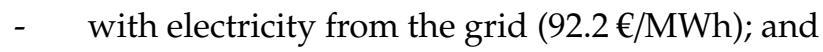

- $\quad$ with electricity from the CHP unit (39.62 $€ / M W h)$.

The data are given in Table 4 . The heat price has been defined as the production price of heat produced from natural gas with hot water boilers.

Table 4. Basic operating data of the high-temperature heat pump (HTHP), energy prices and other economic data.

\begin{tabular}{ccc}
\hline \multicolumn{3}{c}{ Data on Heat Production } \\
\hline Average COP for four HTHP & 5.51 & \\
Average operation power for four HTHP & $86 \%$ & \\
HTHP rated power & $4 \times 500$ & $\mathrm{~kW}_{\text {th }}$ \\
Average heat flow for four HTHP & 1725 & $\mathrm{~kW}_{\text {th }}$ \\
Operating hours per year & 4000 & $\mathrm{~h} / \mathrm{a}$ \\
Yearly heat production with HTHP & 6900 & $\mathrm{MWh} / \mathrm{a}$ \\
Specific electricity consumption of HTHP & 0.18 & $\mathrm{kWh} / \mathrm{kWh}$ \\
\hline Energy Price \\
\hline Heat price & 0.0440 & $\mathrm{EUR} / \mathrm{kWh}$ \\
Electricity price & $0.0397 / 0.0922$ & $\mathrm{EUR} / \mathrm{kWh}$ \\
Erice of heat produced with HTHP & $0.0072 / 0.0167$ & $\mathrm{EUR} / \mathrm{kWh}$ \\
\hline Investment & \\
\hline Discount rate & 650,000 & $\mathrm{EUR}$ \\
\hline
\end{tabular}

The economic calculation using electricity from a cogeneration plant $(39.62 € / \mathrm{MWh})$ is shown in Figure 6. 


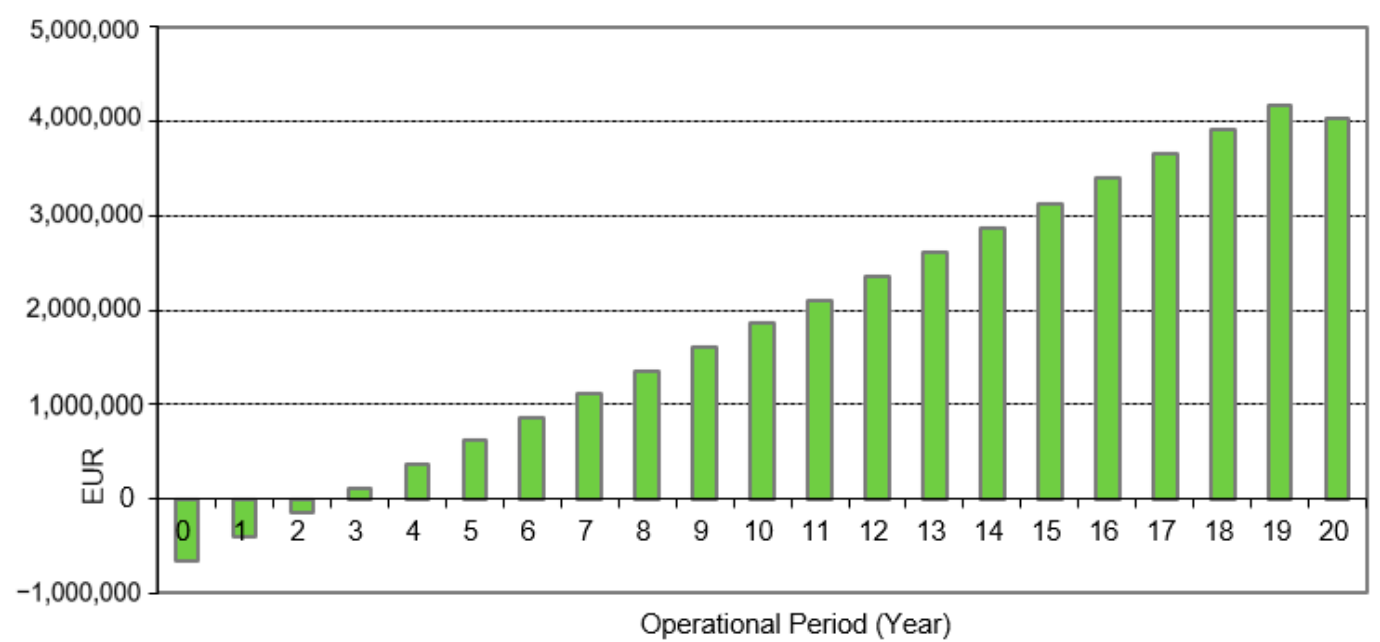

Figure 6. Cumulated discounted cash flow at the price of the electricity at $39.62 € / \mathrm{MWh}$.

Figure 6 shows the internal rate of return (IRR) $=39.3 \%$ and payback of the investment exploiting excess heat from hot water boiler with four series-connected high-temperature heat pumps is less than 3 years.

The economic calculation with the electricity taken from the grid $(92.2 € / \mathrm{MWh})$ is shown in Figure 7.

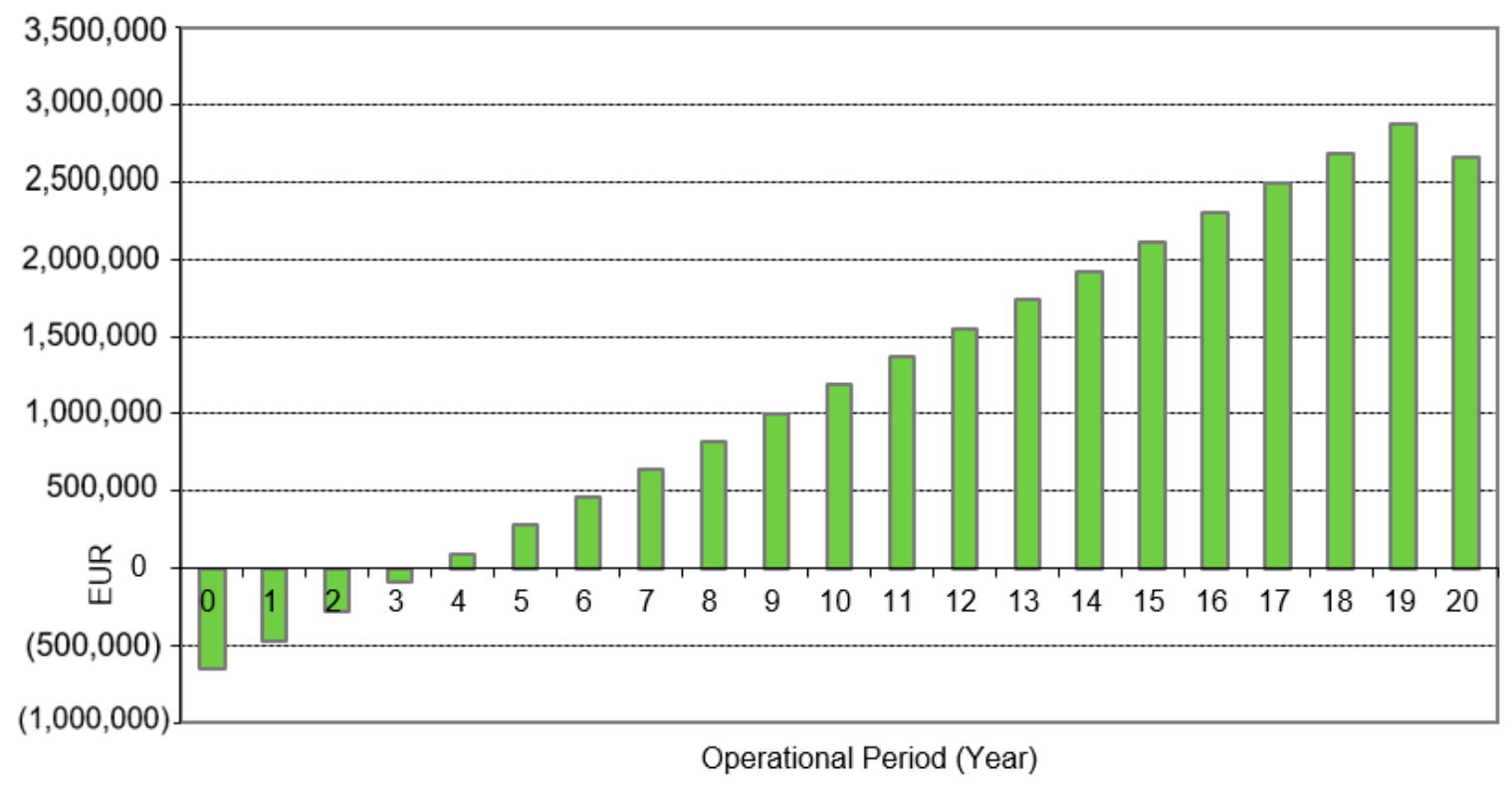

Figure 7. Cumulated discounted cash flow at the price of the electricity at $92.2 € / \mathrm{MWh}$.

The diagram in Figure 7 shows the IRR $=28.8 \%$ and payback of the investment exploiting excess heat from a hot water boiler with four series-connected high-temperature heat pumps is less than 4 years.

\section{Conclusions}

The article presents an innovative technical solution to increase the efficiency of primary fuel and thus reduce $\mathrm{CO}_{2}$ emissions by upgrading existing or new hot water boilers with high-temperature heat pumps that use excess heat from flue gases. The system is suitable for each process in which a hot 
water boiler is installed to raise the energy efficiency of the entire process and consequently reduce the primary fuel consumption and reduce operation costs.

The technology described in the article is new and should be included in national energy efficiency directives and establishing best available techniques (BAT) to increase the primary fuel efficiency of hot water boilers.

In order to exploit the excess heat of the flue gases of the hot water boiler, it is necessary to install a heat exchanger in the flue gas exhaust system, where the water present in the flue gases is additionally cooled by cooling and condensing. The heat produced in this way has temperature too low to be used directly for the needs of high-temperature heating, but it can also be used by using high-temperature heat pumps.

A computer simulation of four series-connected high-temperature heat pumps was undertaken to clearly demonstrate the operation of innovative technology for the exploitation of low-temperature sources of hot water boilers. With an innovative system of sequential connection of high-temperature heat pumps, by utilizing low-temperature heat sources of the hot water boiler, the total primary energy efficiency of natural gas can be increased by $17.6 \%$ (from $90.6 \%$ to $108.2 \%$ compared to LHV of natural gas). This $17.6 \%$ increase in the primary energy efficiency of natural gas is obtained if the flue gases of the hot water boiler are cooled to a temperature of $25^{\circ} \mathrm{C}$.

The energy efficiency of the primary fuel of a hot water boiler can be increased significantly by additional cooling of flue gases (up to approximately $5^{\circ} \mathrm{C}$ ) with the presented technology of serial connection of high-temperature heat pumps.

The presented innovative technical solution is also very economical with a very short return of investment. If the hot water boiler does not reach a sufficiently large number of operating hours, it is necessary to install two heat accumulators in the heating system, where the first accumulates low-temperature heat produced by exploiting excess heat from flue gases, and the second heat accumulator stores heat produced by high-temperature pumps. In this case, the installed power of the heat pumps can also be correspondingly lower, because it will be possible to operate them even when the hot water boiler is not operating.

The operating parameters (hot water boiler and HTHP) of the real system were taken into account in the presented computer simulation.

Author Contributions: Investigation, I.I.; Methodology, D.G.; Supervision, J.K. and D.U. All authors have read and agreed to the published version of the manuscript.

Funding: This research received no external funding.

Conflicts of Interest: The authors declare no conflict of interest.

\section{References}

1. Bergamini, R.; Jensen, J.K.; Elmegaard, B. Thermodynamic competitiveness of high temperature vapor compression heat pumps for boiler substitution. Energy 2019, 182. [CrossRef]

2. European Commission. Best Available Techniques (BAT) Conclusions, under Directive 2010/75/EU of the European Parliament and of the Council, for the Production of Large Volume Organic Chemicals. Off. J. Eur. Union 2004. Available online: http://eur-lex.europa.eu/pri/en/oj/dat/2003/1_285/1_28520031101en00330037. pdf (accessed on 4 November 2020).

3. European Commission. The European Green Deal; European Commission: Luxembourg, 2019.

4. Parliament, E. Energy Efficiency Directive; Official Journal of the European Union: Brussels, Belgium, 2012.

5. Luo, J.; Xue, W.; Shao, H. Thermo-economic comparison of coal-fired boiler-based and groundwaterheat-pump based heating and cooling solution-A case study on a greenhouse in Hubei, China. Energy Build. 2020, 223. [CrossRef]

6. Harmathy, N.; Urbancl, D.; Goricanec, D.; Magyar, Z. Energy efficiency and economic analysis of retrofit measures for single-family residential buildings. Therm. Sci. 2019, 23. [CrossRef]

7. Liu, S.; Li, Z.; Dai, B. Energy, Economic and Environmental Analyses of the CO2 Heat Pump System Compared with Boiler Heating System in China. Energy Procedia 2017, 105, 3895-3902. [CrossRef] 
8. Ala, G.; Orioli, A.; Di Gangi, A. Energy and economic analysis of air-to-air heat pumps as an alternative to domestic gas boiler heating systems in the South of Italy. Energy 2019, 173. [CrossRef]

9. Kozarcanin, S.; Hanna, R.; Staffell, I.; Gross, R.; Andresen, G.B. Impact of climate change on the cost-optimal mix of decentralised heat pump and gas boiler technologies in Europe. Energy Policy 2020, 140. [CrossRef]

10. Calise, F.; Costa, M.; Wang, Q.; Zhang, X.; Duic, N. Recent advances in the analysis of sustainable energy systems. Energies 2018, 11, 2520. [CrossRef]

11. Li, X.; Gao, J.; Zhang, Y.; Zhang, Y.; Du, Q.; Wu, S.; Qin, Y. Energy, exergy and economic analyses of a combined heating and power system with turbine-driving fans and pumps in Northeast China. Energies 2020, 13, 878. [CrossRef]

12. Goričanec, D.; Ivanovski, I.; Krope, J.; Urbancl, D. Improving the efficiency of hot water boilers by using high temperature heat pumps. In Proceedings of the Digital proceedings (SDEWES Latin American Conference on Sustainable Development of Energy, Water and Environment Systems), Buenos Aires, Argentina, 9-20 February 2020.

13. Tanczuk, M.; Masiukiewicz, M.; Anweiler, S.; Junga, R. Technical aspects and energy effects of waste heat recovery from district heating boiler slag. Energies 2018, 11, 796. [CrossRef]

14. Urbancl, D.; Trop, P.; Goricanec, D. Geothermal heat potential-The source for heating greenhouses in Southestern Europe. Therm. Sci. 2016, 20, 1061-1071. [CrossRef]

15. Caf, A.; Urbancl, D.; Trop, P.; Goricanec, D. Exploitation of low-temperature energy sources from cogeneration gas engines. Energy 2016, 108, 86-92. [CrossRef]

16. Korfitsen, E.; Kristensen, A.P.R. Ammonia high pressure heat pumps in food refrigeration applications. Int. J. Refrig. 1998, 21. [CrossRef]

17. No Teureka Success Story. Available online: http://www.eurekanetwork.org/showsuccessstory?p_r_p_ 564233524_articleId=362473\&p_r_p_564233524_groupId=10137 (accessed on 4 November 2020).

18. Darko, G.; Krope, J.; Bozicnik, S. Method and Apparatus for Utilization of Hot Water Plant Waste Heat Recovery by Incorporated High Temperature Water Source Heat Pump. U.S. Patent 15/757,462, 30 August 2018.

19. Global MYCOM. Available online: http://www.mayekawa.eu/ (accessed on 21 November 2020).

20. Blarke, M.B.; Dotzauer, E. Intermittency-friendly and high-efficiency cogeneration: Operational optimisation of cogeneration with compression heat pump, flue gas heat recovery, and intermediate cold storage. Energy 2011, 36. [CrossRef]

21. Blarke, M.B. Towards an intermittency-friendly energy system: Comparing electric boilers and heat pumps in distributed cogeneration. Appl. Energy 2012, 91. [CrossRef]

22. Kapustenko, P.O.; Ulyev, L.M.; Boldyryev, S.A.; Garev, A.O. Integration of a heat pump into the heat supply system of a cheese production plant. Energy 2008, 33. [CrossRef]

Publisher's Note: MDPI stays neutral with regard to jurisdictional claims in published maps and institutional affiliations.

(C) 2020 by the authors. Licensee MDPI, Basel, Switzerland. This article is an open access article distributed under the terms and conditions of the Creative Commons Attribution (CC BY) license (http://creativecommons.org/licenses/by/4.0/). 